\title{
Understanding students' misconceptions: An analysis of final Grade 12 examination questions in geometry
}

\author{
Author: \\ Kakoma Luneta ${ }^{1}$ \\ Affiliation: \\ ${ }^{1}$ Department of Childhood \\ Education, University of \\ Johannesburg, South Africa \\ Correspondence to: \\ Kakoma Luneta \\ Email: \\ kluneta@uj.ac.za \\ Postal address: \\ Private Bag X09, Bertsham \\ 2013, Johannesburg, \\ South Africa \\ Dates: \\ Received: 07 Mar. 2014 \\ Accepted: 26 May 2015 \\ Published: 30 June 2015 \\ How to cite this article: \\ Luneta, K. (2015). \\ Understanding students \\ misconceptions: An analysis \\ of final Grade 12 examination \\ questions in geometry. \\ Pythagoras, 36(1), Art. \#261, \\ 11 pages. http://dx.doi. \\ org/10.4102/pythagoras. \\ v36i1.261 \\ Copyright: \\ (C) 2015. The Authors. \\ Licensee: AOSIS \\ OpenJournals. This work is \\ licensed under the Creative \\ Commons Attribution \\ License.
}

Read online:
The role geometry plays in real life makes it a core component of mathematics that students must understand and master. Conceptual knowledge of geometric concepts goes beyond the development of skills required to manipulate geometric shapes. This study is focused on errors students made when solving coordinate geometry problems in the final Grade 12 examination in South Africa. An analysis of 1000 scripts from the 2008 Mathematics examination was conducted. This entailed a detailed analysis of one Grade 12 geometry examination question. Van Hiele levels of geometrical thought were used as a lens to understand students' knowledge of geometry. Studies show that Van Hiele levels are a good descriptor of current and future performance in geometry. This study revealed that whilst students in Grade 12 are expected to operate at level 3 and level 4, the majority were operating at level 2 of Van Hiele's hierarchy. The majority of students did not understand most of the basic concepts in Euclidian transformation. Most of the errors were conceptual and suggested that students did not understand the questions and did not know what to do as a result. It is also noted that when students lack conceptual knowledge the consequences are so severe that they hardly respond to the questions in the examination.

\section{Introduction}

Geometry is the 'study of shapes, their relationships, and their properties' (Bassarear, 2012, p. 463). It has a long history arising from the practical measurement of land in ancient Egypt and the study of properties of shapes in Greek geometry (Cooke, 2007). Geometry has been identified by research as the field of mathematics that offers 'enormous potential of bringing the subject alive' (Chambers, 2008, p. 187). It is an exploratory subset of the discipline and has links with culture, history, art and design. It is the interactions with these vital human constructs that provide opportunities to make geometry lessons interesting and stimulating (Chambers, 2008). According to González and Herbst (2006), geometry is the only high school subject in which students routinely deal with the necessary consequences of abstract properties and in which students are held accountable for reading, writing and understanding mathematical proofs. Knowledge of geometry remains a prerequisite for study in fields such as physics, astronomy, art, mechanical drawing, chemistry, biology and geology. Atebe and Schäfer (2011) assert that students' general mathematical competencies have been linked closely to their geometric understanding.

Research has also noted that geometry is difficult to teach as well as to learn. Coordinate or analytical geometry, for instance, requires not only geometrical knowledge, but also a vast amount of knowledge in working with coordinates on a 2D (two-dimensional) or 3D (three-dimensional) set of axes. These additional concepts make geometry more complex and require an intricate manner of thinking. Van der Sandt $(2007$, p. 2) concedes that in South Africa geometry is regarded as a 'problematic topic' at secondary school level. Analysing transformation geometry involves many different types of knowledge as defined by Shavelson, Ruiz-Primo and Wiley (2005) and others (e.g. Hiebert, 1986; Rittle-Johnson \& Alibali, 1999) such as procedural, conceptual, strategic and declarative knowledge.

\section{The theoretical framework}

Piaget (1971), supported by Ding and Jones (2006), writes that children's geometrical understanding develops with age and that for children to create ideas about shapes they need physical interaction with objects. Clement, Swaminathan, Hannibal and Sarama (1999, p. 193) assert that 'children's representation of space is constructed through the progressive organisation of the child's motor and internalised actions'. Van Hiele $(1986,1999)$ on the other hand tried to analyse the various aspects involved in the learning of geometry and space.

Van Hiele $(1986,1999)$ introduced the existence of five levels of geometrical thought (Bahr, Bahr \& De Garcia, 2010; Musser, Burger \& Peterson, 2011). For Van Hiele, students develop their 
knowledge of geometry in accordance with these levels. In the first level (visualisation and recognition), students can identify a shape, but are not able to provide its properties. The shape is judged only by its appearance. The second level (analysis) is predominantly descriptive: students are able to identify particular properties of shapes, but not in a logical order. The third level (abstraction and relationships) is informal and deductive: students can combine shapes and their properties to provide a precise definition as well as relate the shape to other shapes. There is a logical order to the properties and they are deduced from one another. The fourth level is more formally deductive: students apply formal deductive arguments such as in proofs. Theorems with an axiomatic system are established. The fifth level (rigour and axiomatics), also known as the meta-mathematical level (Van der Sandt, 2007, p. 1), is characterised by 'formal reasoning about mathematical systems by manipulating geometric statements such as axioms, definitions, and theorems' and at this juncture students can 'compare systems based on different axioms and can study various geometries in the absence of concrete models' (Burger \& Shaughnessy, 1986, p. 31).

Understanding these levels enables teachers to identify the general directions of students' learning and the level at which they are operating (Lim, 2011). The first three levels involve the development of procedural fluency in geometry, whilst the last two display the development of conceptual understanding (Kilpatrick, Swafford \& Findell, 2001). Pegg (1985) explains that Van Hiele's theory is divided into two parts: the first part is the hierarchical sequence of the levels, which shows that each level must be fully developed by the student before proceeding to the next level. The second part is the development of intuition in students and the phases of learning that influence geometric learning.

Van Hiele's levels provide teachers with a framework within which to conduct geometric activities by designing them with the assumptions of a particular level in mind and they are able to ask questions that are below or above a particular level (Lim, 2011; Van de Walle, 2004). The levels are also a good predictor of students' current and future performance in geometry. According to Jones (2003, p. 128), 'the Van Hiele model of mathematical reasoning has become a proved descriptor of the progress of students' reasoning in geometry and is a valid framework for the design of teaching sequences in school geometry'. Van Hiele's (1986) theory of geometry with its focus on geometrical reasoning has been linked to Piaget' five stages of child development and the role they play in learning geometry (Pusey, 2003). Van Hiele's levels of geometrical thought were the guiding principles for studying exiting Grade 12 students' knowledge of transformation geometry and for determining the level at which the average student in the sample operated. Significantly, such information can inform tertiary and vocational institutions as to the instructional support in transformation geometry that students need, as they engage with fundamental mathematics and physics courses. The findings are also crucial to the Grade 12 teachers as the study delineates common conceptual and procedural errors in transformation geometry that they look out for when teaching the topic.

The research question is: What were the most common error that students in Grade 12 displayed in the examination scripts on the geometry question?

\section{Errors in geometry}

School curricula worldwide cover four main learning outcomes in Geometry (Bahr et al., 2010; Bassarear, 2012; Department of Education, 2006). By the time students complete school they should be able to:

- Analyse the characteristics, properties and relationships of two-dimensional and three-dimensional geometrical shapes (Euclidean Geometry).

- Specify locations and describe spatial relationships using coordinate geometry and other representation systems (Coordinate Geometry).

- Apply transformation and use symmetry to analyse mathematical situations (Transformation Geometry).

- Use visualisation, spatial reasoning and geometric modelling to solve problems.

Research has delineated that errors occur mainly because students have difficulties in understanding the instructional strategies adopted by the teacher (Confrey, 1990). In geometry the communication of information at different levels of reasoning of the sender (the teachers) and the receiver (the student) become a major cause of misconception (Lim, 2011). This is especially true in the case of geometry. When the teacher operates and communicates at different levels of geometric thought to those of the students, concepts are not understood or acquired fully. It is necessary for teachers to know their students' level of geometrical thought and to operate at those levels. Michael (2001, p. 11) defines misconceptions as 'conceptual or reasoning difficulties that hinder students' mastery of any discipline'. According to Drews (2005, p. 18), a misconception could be the result of 'a misapplication of a rule, an over- or under-generalization, or an alternative conception of the situation'. Swan (2001, p. 154) views misconceptions as 'natural stage of conceptual development'. For students to be able to confront underlying conceptual difficulties, overcoming misconceptions is required (Van der Sandt \& Nieuwoudt, 2003). Luneta (2008, p. 386) defines errors as 'simple symptoms of the difficulties a student is encountering during a learning experience'.

According to Swan (2001, p. 150), an error could be the result of 'carelessness or misinterpretation of symbols or text'. Misconceptions manifest in students' work as errors, which implies that errors are symptoms of misconceptions students possess. According to Confrey (1990, p. 33) misconceptions emanate from 'a line of thinking that causes a series of errors all resulting from incorrect underlying premises'. Knowledge of students' errors is essential and teachers should provide opportunities for students to display their errors as these will be essential stepping stones for effective instruction. It can 
be argued that knowledge of students' levels of geometric reasoning is essential for effective teaching.

The most common errors in transformation geometry are the result of students operating at levels that are different to their teachers'. It is evident that people reasoning at different levels may not understand each other and this is true for teachers and students. A student reasoning at level $q$ will not understand a teacher reasoning at level $q+1$ (Pusey, 2003). By establishing the levels at which Grade 12 students are operating in transformation geometry, the study hopes to inform university mathematics lecturers on the level of interaction at which to anchor their discourses.

\section{Methodology}

This study conducted an analysis of 1000 Grade 12 mathematics scripts. These were obtained from the Department of Education with this purpose in mind. The scripts were randomly selected from the entire 2008 batch of 108000 scripts. The selection was not based on schools, but was merely an assortment of scripts. After being sampled the 1000 scripts were stratified into three groups according to student ability. Group 3 was made up of students who attained between $0 \%$ and $32 \%(N=333)$, Group 2 obtained between 33\% and 55\% $(N=334)$ and Group 1 between $56 \%$ and $100 \%(N=333)$. The study focused its analysis on the 2008 Grade 12 National Examination Paper 2 Question 3 (see Appendix). This question is made up of seven parts that assess student knowledge of different aspects of geometry. The study used a content analysis technique in which each question was analysed according to the content it contained (students errors). According to Berelson (1952), content analysis is a technique used for objective, systematic and quantitative description of the manifest content of communication. Kerlinger (1986) emphasises content analysis as a method for studying and analysing communication in a systematic, objective and quantitative manner for the purpose of measuring variables. In this instance the student answers are an indication of their ability to interact with geometry examination questions. The variable being measured is their responses (misconception and the associated errors) against the correct answers. The analysis made inferences to the communication (student's answers) by systematically and objectively identifying specific characteristics of the student's errors in the answers. This study was encapsulated in the epistemological framework of constructivism and the theoretical perspective of interpretivism. This implied that the study viewed learning as being informed by both the students and the teacher. This means that the interpretation of the students' understanding of mathematics was pivotal to the theory that was developed. The unit of analysis was the errors students displayed on each of the seven parts of Question 3 (Appendix 1). The students' errors were classified as conceptual errors - or those errors that were due to nonconceptual understanding of the concept - and procedural errors - these were errors that were related to the incorrect use of the procedure to solve the problem. This included the inappropriate use of formulae, application errors, which are errors that apply to the misuse of rules, and careless errors, which are those that students made unknowingly and which could be corrected by the student if they were so prompted (Luneta \& Makonye, 2011).

\section{Synopsis of student responses to the questions}

Table 1 provides a synopsis of how the three groups answered the seven parts of Question 3. The first analysis focused on 'correctly answered' questions and classified the responses from the three groups of students into three

TABLE 1: Students' attempts to answer Question 3.

\begin{tabular}{|c|c|c|c|c|c|c|}
\hline Question 3: Transformation geometry & $\begin{array}{c}\text { Cognitive demand level } \\
\text { (K/RP/CP/PS) }\end{array}$ & Van Hiele levels & $\begin{array}{l}\text { Correctly } \\
\text { answered }\end{array}$ & Partially correct & Incorrect & Not answered \\
\hline \multirow{3}{*}{$\begin{array}{l}3.1 .1 \\
\text { Reflection in line } y=x\end{array}$} & \multirow[t]{3}{*}{ K } & \multirow[t]{3}{*}{1} & $85,0 \%$ Group 1 & $0,0 \%$ Group 1 & $15,0 \%$ Group 1 & $0,0 \%$ Group 1 \\
\hline & & & $50,0 \%$ Group 2 & $0,0 \%$ Group 2 & $47,5 \%$ Group 2 & $2,5 \%$ Group 2 \\
\hline & & & $13,0 \%$ Group 3 & $0,0 \%$ Group 3 & $74,0 \%$ Group 3 & $13,0 \%$ Group 3 \\
\hline \multirow{3}{*}{$\begin{array}{l}3.1 .2 \\
\text { Rotation about origin } \\
\text { through } 180^{\circ}\end{array}$} & \multirow[t]{3}{*}{ K } & \multirow[t]{3}{*}{2} & $85,8 \%$ Group 1 & $0,0 \%$ Group 1 & $14,2 \%$ Group 1 & $0,0 \%$ Group 1 \\
\hline & & & $59,8 \%$ Group 2 & $0,0 \%$ Group 2 & $36,5 \%$ Group 2 & $3,7 \%$ Group 2 \\
\hline & & & $8,0 \%$ Group 3 & 0,0\% Group 3 & $72,0 \%$ Group 3 & $20,0 \%$ Group 3 \\
\hline \multirow{3}{*}{$\begin{array}{l}3.2 .1 \\
\text { Coordinates of point rotated } \\
90^{\circ} \text { about origin clockwise }\end{array}$} & \multirow[t]{3}{*}{ K } & \multirow[t]{3}{*}{2} & $89,0 \%$ Group 1 & $0,0 \%$ Group 1 & $11,0 \%$ Group 1 & $0,0 \%$ Group 1 \\
\hline & & & $57,0 \%$ Group 2 & $0,0 \%$ Group 2 & $42,5 \%$ Group 2 & $<1,0 \%$ Group 2 \\
\hline & & & 7,0\% Group 3 & $0,0 \%$ Group 3 & $90,0 \%$ Group 3 & $3,0 \%$ Group 3 \\
\hline \multirow{3}{*}{$\begin{array}{l}3.2 .2 \\
\text { Rotation of polygon } 90^{\circ} \text { about } \\
\text { origin in clockwise direction } \\
\text { and stretch }\end{array}$} & \multirow[t]{3}{*}{$\mathrm{RP}$} & \multirow[t]{3}{*}{2} & $85,0 \%$ Group 1 & 0,0\% Group 1 & $15,0 \%$ Group 1 & $0,0 \%$ Group 1 \\
\hline & & & $49,8 \%$ Group 2 & $0,0 \%$ Group 2 & $50,2 \%$ Group 2 & $0,0 \%$ Group 2 \\
\hline & & & 2,5\% Group 3 & 0,0\% Group 3 & $84,5 \%$ Group 3 & $13,0 \%$ Group 3 \\
\hline \multirow{2}{*}{$\begin{array}{l}3.2 .3 \\
\text { Enlargement of polygon by } \\
\text { scale factor of } k\end{array}$} & \multirow[t]{2}{*}{ K } & \multirow[t]{2}{*}{2} & $93,0 \%$ Group 1 & $0,0 \%$ Group 1 & 7,0\% Group 1 & $0,0 \%$ Group 1 \\
\hline & & & $34,0 \%$ Group 3 & $0,0 \%$ Group 3 & $54,0 \%$ Group 3 & $12,0 \%$ Group 3 \\
\hline \multirow{3}{*}{$\begin{array}{l}3.2 .4 \\
\text { Transformation rule (rotation of } 90^{\circ} \\
\text { clockwise and then enlargement) }\end{array}$} & \multirow[t]{3}{*}{$\mathrm{CP}$} & \multirow[t]{3}{*}{3} & $84,0 \%$ Group 1 & $15,5 \%$ Group 1 & $0,0 \%$ Group 1 & $<1,0 \%$ Group 1 \\
\hline & & & $33,0 \%$ Group 2 & $37,0 \%$ Group 2 & $25,0 \%$ Group 2 & 5,0\% Group 2 \\
\hline & & & $3,0 \%$ Group 3 & $5,0 \%$ Group 3 & $73,0 \%$ Group 3 & $19,0 \%$ Group 3 \\
\hline \multirow{3}{*}{$\begin{array}{l}3.2 .5 \\
\text { Comparison of areas of polygon and its } \\
\text { image after enlargement }\end{array}$} & \multirow[t]{3}{*}{$\mathrm{RP}$} & \multirow[t]{3}{*}{4} & $44,0 \%$ Group 1 & 4,0\% Group 1 & $47,0 \%$ Group 1 & $5,0 \%$ Group 1 \\
\hline & & & $9,0 \%$ Group 2 & 7,3\% Group 2 & $60,7 \%$ Group 2 & $23,0 \%$ Group 2 \\
\hline & & & $2,0 \%$ Group 3 & $0,0 \%$ Group 3 & $81,0 \%$ Group 3 & $17,0 \%$ Group 3 \\
\hline
\end{tabular}

CP, complex problems; K, knowledge; PS, problem solving; RP, routine procedures. 
categories: 'partially answered' questions, 'incorrectly answered' questions and 'not answered' questions. Using Van de Walle's (2004, p. 346) classifications of the products that emanate from Van Hiele's thoughts the researcher was able to classify the questions accordingly. Van de Walle's classification defines the levels as: level 1, the products of thought are classes or grouping of shapes that seem alike; level 2, the products of thought are the properties of shapes; level 3, the products of thought are relationships amongst properties of geometric objects; level 4, the products of thought are deductive axiomatic systems of geometry; level 5 , the products of thought are comparison and contrasts amongst different systems of geometry (Van der Sandt \& Nieuwoudt, 2003).

Table 1 shows that the question on transformation geometry required students to operate at the knowledge level of Bloom's taxonomy (evaluation, synthesis, analysis, application, comprehension and knowledge). The third column shows the Van Hiele levels products of thought for each question derived from Van de Walle (2004). Students in Group 3 had the highest number of 'not answered' questions, students in Group 1 had the highest number of 'correctly answered' questions (85\%) and those in Group 2 had the highest number of 'partially answered' questions. It was also evident that Group 1 students had the highest number of 'common mistakes or careless errors'. This was due to the fact that they attempted most of the questions. The middle group had the highest number of procedural errors. Most students in Group 3 did not attempt the questions, so it was not easy to identify their errors. It can however be assumed that since Group 3 could not provide answers to most of the questions, they lacked conceptual understanding of the concept of transformation geometry. Table 1 also shows that the majority of the students were operating below level 2 of Van Hiele's levels of geometric thought and that only $44 \%$ of Group 1 could operate at level 4 . Figure 1 is developed from column 3 and column 4 in Table 1 . The figure illustrates that only $493(49,3 \%)$ students could respond correctly to question 3.1.1, pegged at level 1 of Van Hiele's levels of geometric thought. It further depicts that $539(53,9 \%)$ students could respond correctly to questions 3.1.2, 3.2.1, 3.2.2 and 3.2.3, pegged at level 2, only $400(40 \%)$ students could respond correctly to question 3.2.4 that was pegged at level 3 and only $183(18 \%)$ students could respond to a question pegged at level 4 of Van Hiele's levels of geometric thought.

It is worth noting that the sixth column (incorrect) of Table 1 would have produced the converse of Figure 1 where Group 3 would have had the highest bars and Group 1 the shortest bars depicting incorrect answers.

\section{Question by question analysis of students' errors \\ Question 3.1.1}

Students were required to give the coordinates of the image of a point after reflection in the line $y=x$. According to Table 1 students operating at Van Hiele level 1 would

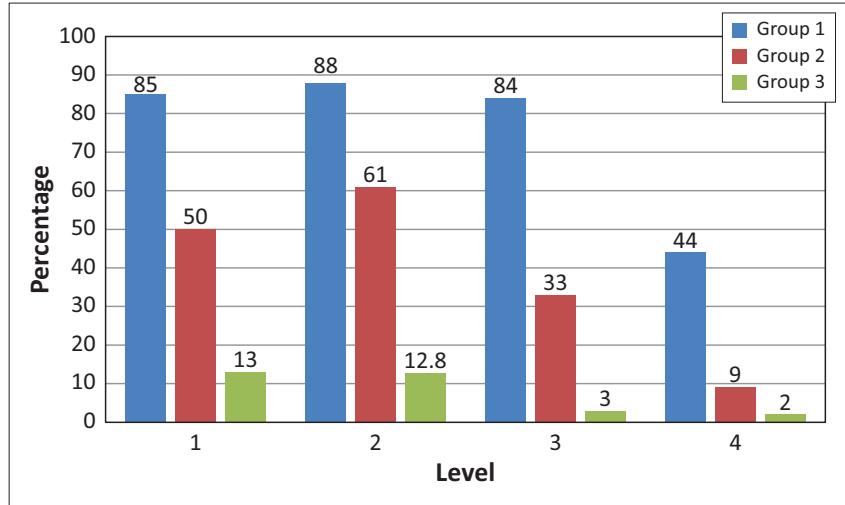

FIGURE 1: Student groups' average Van Hiele levels of geometric thought on the questions.

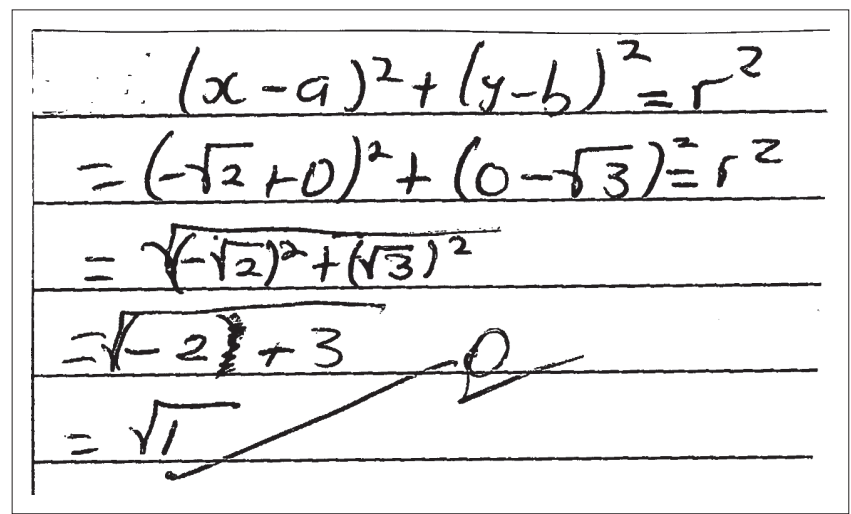

FIGURE 2: A formula not related to the question that was asked (E3.1.1A).

be able to respond to this question. The majority of the Group 1 students were able to answer this question, whereas only $13 \%$ of the group 3 learners managed. Many learners gave coordinates suitable for a $180^{\circ}$ rotation or a reflection in the $y$-axis. This implied that the majority of the students who completed the examination could not differentiate between the lines $y=x$, the $x$-axis or the $y$-axis. There were a number of students who demonstrated a total lack of understanding of what the question was about. The example (see Figure 2) (E3.1.1A = Error in question 3.1.1 part A) shows a student using a formula that was hardly related to the question. Thirty percent of the Group 3 students did not offer a feasible answer (i.e. they did not understand that the question was asking for the coordinates of a point). Conceptually the majority of students did not know the line $y=x$ and therefore could not correctly reflect the object on that line.

\section{Question 3.1.2}

Table 1 shows that to respond to this question correctly students need to operate at Van Hiele level 2. This question required students to give the coordinates of the image of a point after undergoing a $180^{\circ}$ rotation. Once again, this question was answered correctly by most students in Group 1. By contrast,20\% of students in Group 3 did notattempt the question and a further $72 \%$ of these students got the answer wrong. An analysis of the students' responses showed that most of them did not understand the question and therefore did not know what to do. Many students wrote coordinates for $\mathrm{P}^{\prime}$ that did not resemble the original coordinates of point 
P. It seemed as if some students confused the transformation rule for a reflection in $y=-x$ with the rule for a $180^{\circ}$ rotation: they used the rule $(x ; y) \rightarrow(-y ;-x)$ instead of $(x ; y) \rightarrow(-x ;-y)$. This question entailed a gradual geometric move from analysis to abstract levels of geometrical thought. But the low performance on question 3.1.1 showed that most Grade 12 students could not operate at Van Hiele level 2 or above. The major misconception in this question was that the students could not differentiate the operative rules required for reflection, rotation and translation - rules of rigid transformation in Euclidian geometry.

\section{Question 3.2.1}

In this question, students were asked to give the coordinates of a point after a $90^{\circ}$ rotation in a clockwise direction. This question also required students to operate at Van Hiele level 2. Nine percent of the sample group rotated $\mathrm{D}$ in an anti-clockwise direction. Twenty percent of the group reflected $\mathrm{D}$ about the $x$-axis and $13 \%$ reflected $\mathrm{D}$ about the $y$-axis. The common errors showed the students' lack of knowledge of the difference between rotation and reflection.

\section{Question 3.2.2}

Table 1 again shows that students were required to operate at Van Hiele level 2 in order to be able to answer this question. This routine question required students to draw a sketch of a polygon after rotating it $90^{\circ}$ in a clockwise direction. Only $25 \%$ of the students got this question correct and these were from Group 1. The most common error made was a reflection about the $x$-axis. These students probably tried to rotate the polygon in a clockwise direction, but did not understand that the polygon's orientation in space needed to change as well. Some students reflected the polygon about the $y$-axis (probably in an attempt to rotate it in an anticlockwise direction). This shows that these students had the same misconception regarding the rotation of a rigid shape. A significant number of students were not able to transform the polygon without altering its shape or size and others rotated the polygon $180^{\circ}$ or translated it. It showed that most of the students (75\%) could not tell the difference between a rotation, a reflection and a translation. In fact, it meant that they could not tell the difference between a rigid and a non-rigid transformation. Figure 3 shows an example of the conceptual errors the majority of the students made.

Below are three more examples of the various errors that students made regarding this question; they all show lack of knowledge of transformation geometry. The student's work on the immediate left is a reflection on the $y$-axis but the coordinates are wrong. The $x$-coordinates are depicted as $y$ coordinates and vice versa. This was very common amongst most students in both Group 3 and Group 2 despite the fact that basic coordinate geometry is learnt at primary school: 'plotting, reading and writing coordinates, Year 2' (Hansen, Drews \& Dudgeon, 2014, p. 170). The example on top right is from a Group 1 student who seems to have knowledge of rotation but does an anti-clockwise rotation of $90^{\circ}$, which was not what was asked.

Figure 4 further shows that a number of students did not understand the principle that rotation, like reflection and translation, is a rigid transformation. Such an answer was common in many (72\%) of the students' scripts; this is despite the fact that translation, reflection and basic rotation are taught at foundation phase (Hansen et al., 2014).

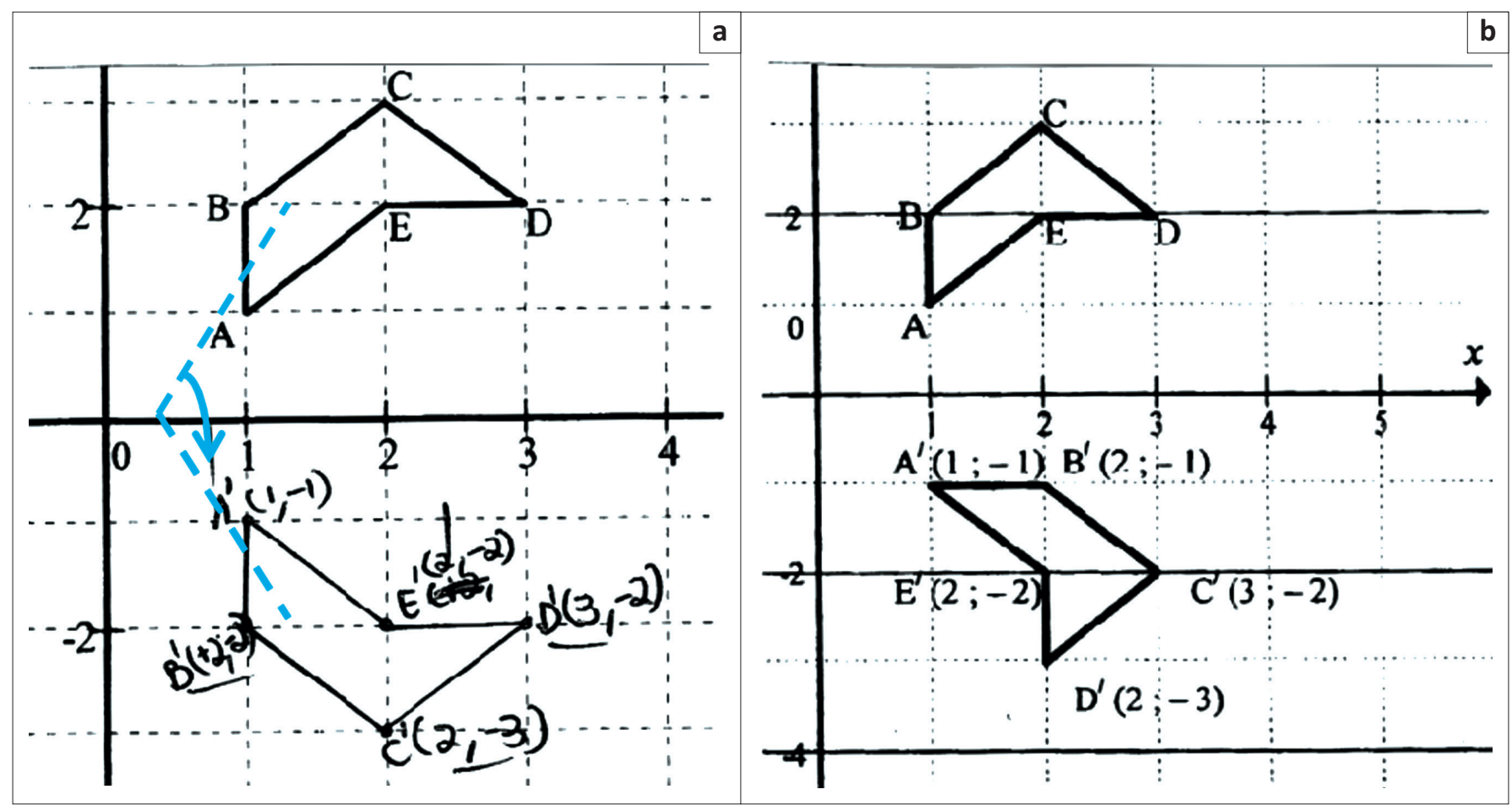

FIGURE 3: Typical student conceptual error on 3.2.2 (a) and the memorandum (b) 

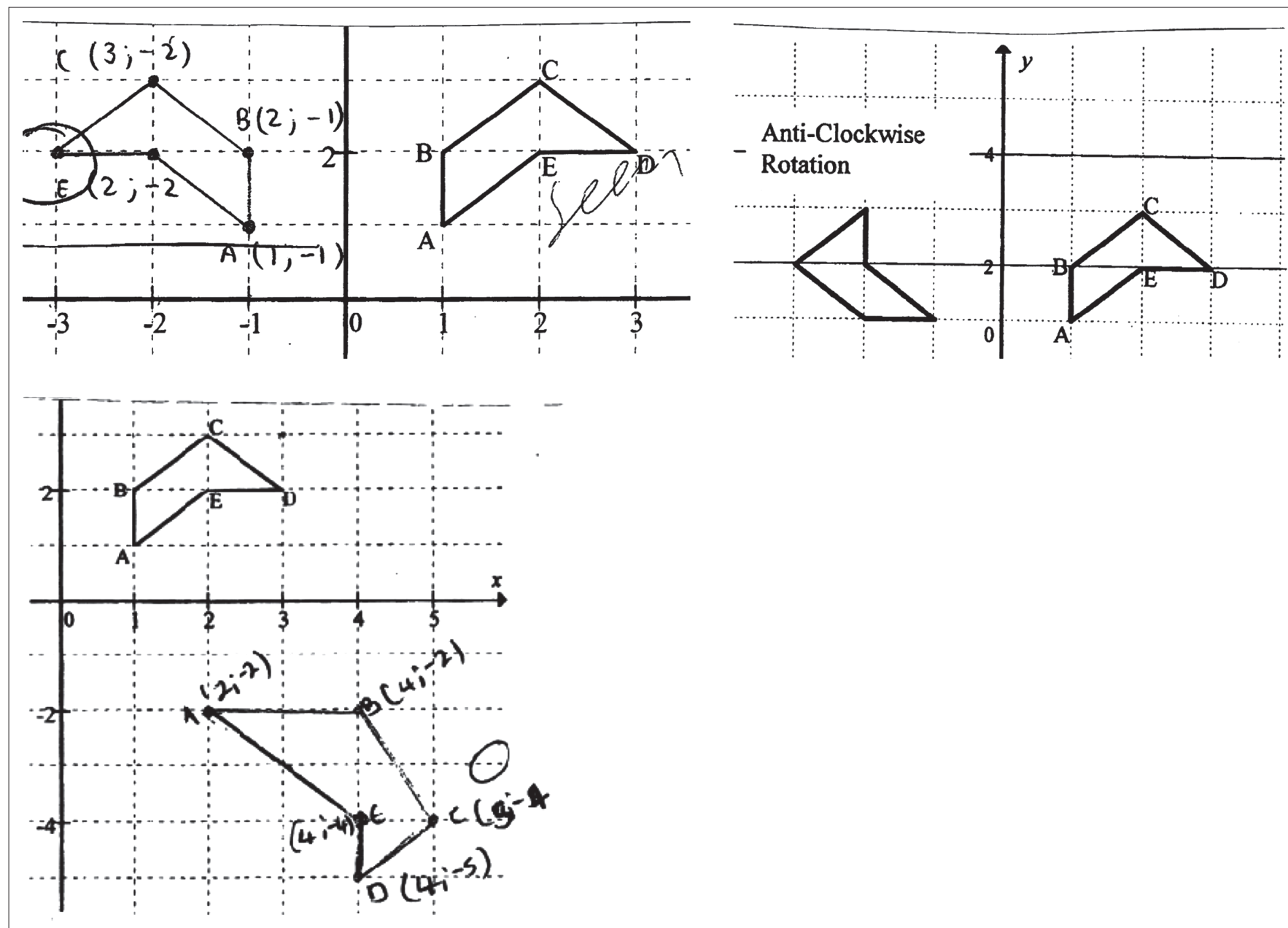

FIGURE 4: Students lack of knowledge of rigid transformation (E3.2.2D).

\section{Question 3.2.3}

This question required students to enlarge a polygon by a given factor and find the image of enlargement. More than half of the students answered the question correctly (method marks were often awarded following on from their answers to question 3.2.1). Students were asked to give the coordinates of $\mathrm{D}^{\prime \prime}$ after enlarging the polygon by a factor of 3 through the origin. It was difficult to analyse the incorrect answers, as often the given values were not related to the coordinates of $\mathrm{D}$ or $\mathrm{D}^{\prime}$. This implies that students were not conceptually grounded on transformation that involved enlargement and whilst Table 1 shows that the question required them to operate at level 2 of the Van Hiele hierarchy, they were predominantly operating at level 1 as can be seen from Table 2 .

\section{Question 3.2.4}

For this question, students had to create a transformation rule for the combination of the two transformations in 3.2.1 and 3.2.3. Table 1 shows that this question was at level 3 of the Van Hiele levels of geometrical thought (abstraction and deduction). Because of its high cognitive demand, less than $50 \%$ of students in Group 1 and very few in Group 2 and Group 3 managed to answer this question correctly. It is not surprising to note that $13 \%$ of the sampled students did not attempt this question and 50\% did not write an appropriate response. This question involved complex thought procedures, but is an examination question that Grade 12 students are reasonably expected to tackle. The students who understood what the question required managed to write a transformation rule to represent the enlargement by a factor of 3 , but few could represent the rotation of $90^{\circ}$ algebraically. A typical partially correct answer was $(x ; y) \rightarrow(3 x ; 3 y)$.

\section{Question 3.2.5}

To respond to this question students needed to operate at level 4 of the Van Hiele hierarchy according to Table 1. Approximately $18.3 \%$ of the sample group got this question correct. Thirteen percent of the students stated that the area $A B C D E$ :area $A^{\prime \prime} B^{\prime \prime} C^{\prime \prime} D^{\prime \prime} E$ " is 1:3. A few of the students understood theimplications of scalingthearea, butdidnotwrite the ratio correctly (i.e. area ABCDE:area A" $\mathrm{B}^{\prime \prime} \mathrm{C}^{\prime \prime} \mathrm{D}^{\prime \prime} \mathrm{E}^{\prime \prime}=1: 9$ ). Half of the students were not able to use an appropriate method to address this question. In some instances students used incorrect formulae to determine the answer as shown in Figure 5. $A^{\prime \prime} \mathrm{B}^{\prime \prime} \mathrm{C}^{\prime \prime} \mathrm{D}^{\prime \prime} \mathrm{E}$ " is the result of enlarging $\mathrm{ABCDE}$ by a factor of 3 ; therefore, the ratio of the image and the object is 3:1 and ratio of their area will be the square of these units. Figure 1 shows that this was the most difficult question amongst the majority the students sampled, such that even in 
Group 1 only 44\% got it right. Students' answers ranged from an attempt to finding an area of a triangle such as the first answer in Figure 5 to unknown mathematical manipulations that did not make sense at all as can be seen in the second answer in which the student was adding $x$ and $y$ coordinates.

Table 2 shows students' common errors on each question and their identified Van Hiele levels. Van der Sandt and Nieuwoudt (2003, p. 200) confirm that 'students' answers can be classified according to the Van Hiele levels of thinking they reflect by using description levels provided by the mathematical accuracy and how complete the solution to the activity is'. From the students' errors the table also shows

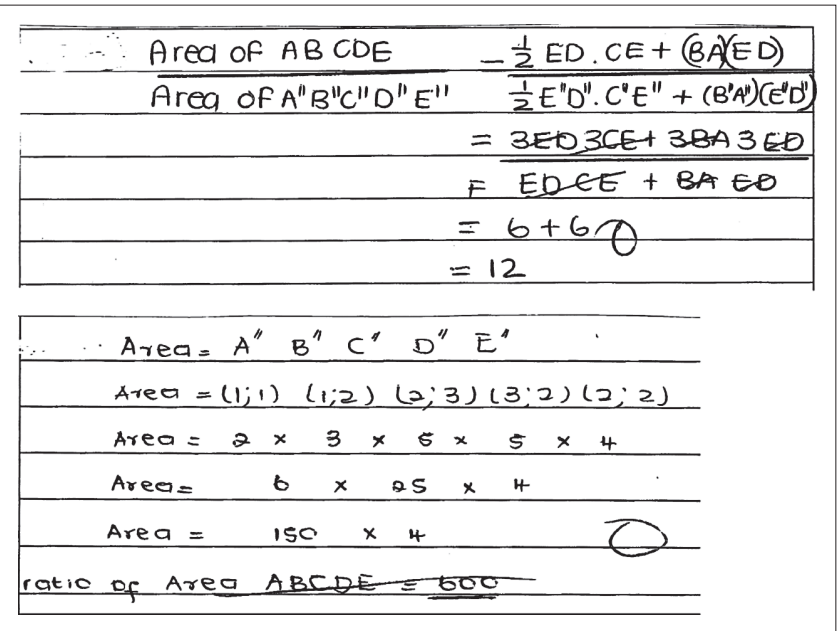

FIGURE 5: Students' errors that were not related to the question (E3.2.5E). the researchers' identified products of thought (description levels) and their resultant Van Hiele levels.

\section{Discussion}

Table 2 shows that students in the sample were mostly operating at level 1 of Van Hiele's levels of geometric thought. By contrast, Table 1 shows that in order for the students to respond correctly to all the questions except 3.1.1, they needed to operate at level 2 or above. Furthermore, research (Luneta, 2014, p. 80) suggests 'that learners who successfully complete Grade 12 should be operating at level 3 of the Van Hiele theory'. It is possible to suggest that most students in Grade 12 operate at or below level 2 of the Van Hiele hierarchy. There are several reasons for this. For instance, according to Van der Lith (2007), there are two ways of finding the equation of a straight line: using the formula $y-y_{1}=m\left(x-x_{1}\right)$ or the general form $y=m x+c$. Connecting the procedure of the gradient and the equation of a straight line is essential for deducing the equation (this is understanding), but the majority of students could not solve a straight line problem, despite the fact that graphs of a straight line are taught in Grade 9 (Bassarear, 2012, p. 545).

According to the curricula, transformation geometry (translation, reflection and rotation) is introduced and taught at primary school (Bassarear, 2012, p. 545). It is disconcerting that the majority of students in Grade 12 could not solve tasks that are gauged to be at a Grade 7 level of accomplishment and at level 2 on Van Hiele's hierarchy of geometrical understanding. Question 3.2.4 on enlargement

TABLE 2: Explanations of students' average errors on each of the seven parts of Question 3 and the resultant Van Hiele classification.

\begin{tabular}{|c|c|c|c|c|c|}
\hline \multirow{2}{*}{$\begin{array}{l}\text { Identified learners' } \\
\text { Van Hiele levels } \\
1\end{array}$} & \multicolumn{5}{|l|}{ Error analysis key on Question 3} \\
\hline & E3.1.1A & E3.1.1B & E3.1.1C & E3.1.1D & \\
\hline & $\begin{array}{l}\text { Student appears to have } \\
\text { rotated } \mathrm{P} 180^{\circ} \text { : }\end{array}$ & $\begin{array}{l}\text { Coordinates have been } \\
\text { swapped, but error made }\end{array}$ & $\begin{array}{l}\text { Student appears to have } \\
\text { reflected P about the } y \text {-axis }\end{array}$ & $\begin{array}{l}\text { Inappropriate method used or } \\
\text { coordinates unrelated to those of P. }\end{array}$ & \\
\hline & $\begin{array}{l}(x ; y) \rightarrow(-x ;-y) \\
\text { i.e. } \mathrm{P}(\sqrt{2} ;-\sqrt{3})\end{array}$ & $\begin{array}{l}\text { with signs, e.g. } \\
(\sqrt{3} ; \sqrt{2}) \text { or }(-\sqrt{3} ; \sqrt{2}) \text { or }(-\sqrt{3} ;-\sqrt{2}) \text {. }\end{array}$ & & & \\
\hline \multirow[t]{3}{*}{1} & E3.1.2A & E3.1.2B & E3.1.2C & E3.1.2D & \\
\hline & \multirow{2}{*}{$\begin{array}{l}\text { Student appears to have } \\
\text { reflected } \mathrm{P} \text { about } y=x \\
\text { i.e. }(\sqrt{3} ;-\sqrt{2}) .\end{array}$} & \multirow[t]{2}{*}{$\begin{array}{l}\text { Coordinates of } P \text { given, } \\
\text { i.e. }(-\sqrt{ } 2 ; \sqrt{3}) \text {. }\end{array}$} & $\begin{array}{l}\text { Student appears to have } \\
\text { reflected }\end{array}$ & \multirow[t]{2}{*}{$\begin{array}{l}\text { Unusual method or unrelated } \\
\text { coordinates. }\end{array}$} & \\
\hline & & & P about $y=-x$, i.e. $(-\sqrt{3} ; \sqrt{2})$. & & \\
\hline \multirow[t]{2}{*}{1} & E3.2.1A & E3.2.1B & E3.1.2C & E3.1.2D & \\
\hline & $D^{\prime}(3 ;-2)$ & $D^{\prime}(2 ;-3)$ & $D^{\prime}(-3 ; 2)$ & $\begin{array}{l}\text { Unusual method or unrelated } \\
\text { coordinates. }\end{array}$ & \\
\hline \multirow[t]{2}{*}{2} & E3.2.2A & E3.2.2B & $\mathrm{E3} .2 .2 \mathrm{C}$ & E3.2.2D & \\
\hline & $\begin{array}{l}\text { Polygon has not been rotated } \\
\text { (it has been reflected on the } \\
x \text {-axis). }\end{array}$ & $\begin{array}{l}\text { Polygon has been rotated } 90^{\circ} \\
\text { anticlockwise. }\end{array}$ & $\begin{array}{l}\text { The polygon has not been } \\
\text { rotated (it has been reflected } \\
\text { on } y \text {-axis). }\end{array}$ & $\begin{array}{l}\text { Inappropriate transformation (e.g. } \\
\text { rotation of } 180^{\circ} \text {, shape not preserved, } \\
\text { translation, rotation about point on } \\
\text { the polygon or strange method). }\end{array}$ & \\
\hline \multirow[t]{2}{*}{1} & E3.2.3A & E3.2.3B & & & \\
\hline & $\begin{array}{l}\text { Coordinates } \mathrm{D}^{\prime \prime} \text { not related } \\
\text { to } \mathrm{D}^{\prime} \text {. }\end{array}$ & $\begin{array}{l}\text { Unusual method or unrelated } \\
\text { coordinates. }\end{array}$ & & & \\
\hline \multirow[t]{3}{*}{2} & E3.2.4A & E3.2.4B & E3.2.4C & E3.2.4D & \\
\hline & $\begin{array}{l}\text { Student understands the } \\
\text { concept of enlargement, i.e. }\end{array}$ & $\begin{array}{l}\text { Student understands the } \\
\text { concept of rotation, i.e. }\end{array}$ & \multirow{2}{*}{$\begin{array}{l}\text { Transformation rule not } \\
\text { given (student has applied } \\
\text { transformation to actual } \\
\text { coordinates). }\end{array}$} & \multirow[t]{2}{*}{ Inappropriate transformation. } & \\
\hline & $\begin{array}{l}(x ; y) \rightarrow(3 x ; 3 y) \text {, but not able } \\
\text { to give the rule for rotation. }\end{array}$ & $\begin{array}{l}(x ; y) \rightarrow(y ; x), \text { but not able to } \\
\text { give the rule for enlargement. }\end{array}$ & & & \\
\hline \multirow[t]{3}{*}{1} & E3.2.5A & E3.2.5B & E3.2.5C & E3.2.5D & E 3.2.5E \\
\hline & \multirow[t]{2}{*}{ Ratio of 1:6 } & \multirow[t]{2}{*}{ Ratio of 1:3 } & \multirow[t]{2}{*}{$\begin{array}{l}\text { Other ratios }(1: 4 ; 1: 8 \\
1: 16 ; 1: 2)\end{array}$} & \multirow{2}{*}{$\begin{array}{l}\text { Student understands the concept of } \\
9 \times \text { as being magnification but ratio } \\
\text { expressed backwards, i.e. 9:1, or not } \\
\text { given as a ratio. }\end{array}$} & $\begin{array}{l}\text { Inappropriate } \\
\text { method used. }\end{array}$ \\
\hline & & & & & Level 1 \\
\hline
\end{tabular}


is equivalent to a Grade 7 question, which requires students to find the image of a polygon by multiplying the coordinates of the original polygon by 3 (Bassarear, 2012, p. 546). Of the seven questions, only question 3.2 .5 was at a level higher than level 2 of Van Hiele's levels of geometrical thought. The results show that most students did not have basic knowledge of geometry, such as the meaning and characteristics of the three rigid geometric transformations of reflection, translation and rotation. Students swapped rules that governed reflection with those that dealt with rotation or translation. This means that students did not seem to know the difference between the three transformations. The findings of this study are consistent with other studies in South Africa (Atebe \& Schäfer, 2011; Siyepu, 2005), which also found that the majority of learners were operating at the pre-recognition level and that a very small number of students operated at Van Hiele's second level. The study further showed that students enter university operating at a level of geometric thinking that is not appropriate for learning the university mathematics curriculum, which requires students to have reached level 4 and level 5 (Lim, 2011). Some of the explanations of this problem is that geometry is not taught very well from primary school onwards. De Villiers (1998) asserts that 'unless we embark on a major revision of the primary school geometry curriculum along the lines of Van Hiele's hierarchy, it seems clear that no amount of effort at the secondary school will be successful'. Geometry at level 1 should be based on perception of the concepts involved, which at primary school entails the identification of polygons and their properties and nonstandard orientations.

For instance, a student fixated on the natural shape of a trapezoid will fail to notice that all three figures in Figure 6 are in actual fact trapezoids.

Teaching geometry to learners in a standardised way leaves them incapacitated when a change in the natural orientation of a figure is affected. For instance, in Figure 7a both figures are squares but many students would think the first figure is not a square (but a rhombus) because that is the conventional

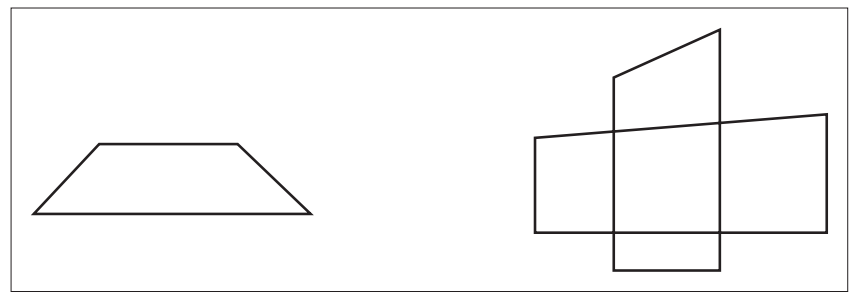

FIGURE 6: Different orientations of trapezoids.

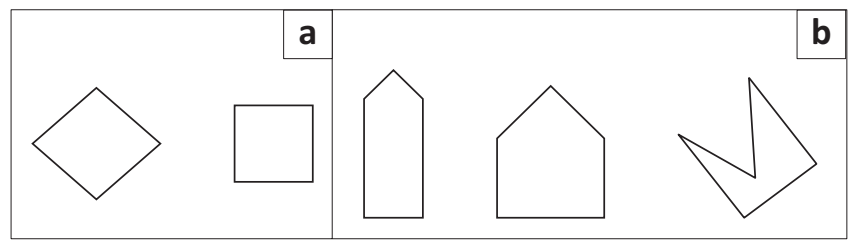

FIGURE 7: Different orientations of a square and a pentagon. way that a rhombus has been presented to them. The figures in Figure $7 \mathrm{~b}$ are all pentagons, but most students are familiar only with the first orientation, because that is how most teachers and textbooks represent a pentagon.

The most common errors were procedural. Students were not able to engage with simple geometric relationships, reflections about a particular line, rotation of shapes in standard angles of $90^{\circ}, 180^{\circ}$ and $360^{\circ}$ about a specific point. Every question answered had a higher occurrence of procedural errors than common mistakes or conceptual errors. Whilst there is no evidence from this study to back up this point, other research (Hansen et al., 2014; Van der Sandt, 2007) asserts that the main explanation why a number of students are fluent in the use of procedural methods to answer mathematics questions is because that is the most dominant way that many teachers teach mathematics. The majority of mathematics teachers hardly explain concepts in ways that enable students to acquire conceptual understanding that leads to conceptual knowledge. Hansen et al. (2014, p. 156) assert that students were less likely to notice attributes of shapes in geometry 'because [of] the conventional way geometry is being taught'.

The study concurs with research (Centre for Development in Education, 2010) on teachers that points to the fact that most mathematics teachers in South Africa do not have the appropriate skills, content knowledge, as well as the pedagogical content knowledge, necessary to be effective in a mathematics classroom. Most mathematics teachers do not seem to have the knowledge and instructional skills required to explain concepts, but rather their teaching consists of algorithms that students are instructed to follow. Researchers (Verschaffel, Greer \& De Corte, 2000) assert that the root cause of the lack of mathematical skills and conceptual understanding, which results in a cognitive deficit amongst mathematics students, is not their failure to acquire these skills, but rather the tendency to revert to 'rules of the game': the teachers and the textbooks present mathematics in simplistic, solvable, uncontroversial operations or procedures where there is only one precise correct answer, which can be obtained by performing one mathematical operation. A number of textbooks and teachers explain the concept in a routinised and standardised way. For instance, most texts introduce the concepts of angles at the centre and on a circle by having the subtended angle always facing upwards and subtended by the minor arc as in Figure $8 b$ rather than Figure 8a (Hansen, et al., 2014).

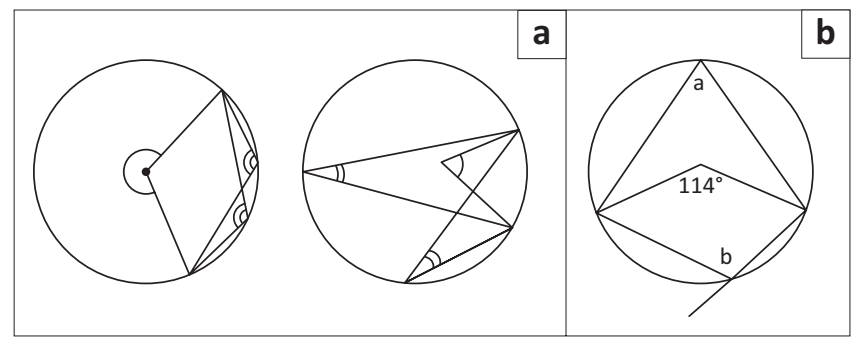

FIGURE 8: The angle subtended by an arc at the centre is twice the angle subtended on the circle. 
Lim (2011) concedes that transition from level 2 to level 3 is even harder for students, but it is a goal of all mathematics teachers for students to attain level 3 at the end of their secondary schooling. If they do not achieve this, they will only have a superficial understanding of geometry and will regard it as a bundle of unrelated concepts, rules and properties. The transition from level 2 to level 3 is acquired by students responding to 'why' questions and justifying their reasons, for instance 'why this is a rotation and not a reflection?', 'why it is an enlargement and a translation?' 'why it is a polygon and not a polyhedron?'.

\section{Conclusion}

This study confirmed, on the one hand, previous findings of the literature (a confirmatory study); on the other hand, it explored thinking in geometrical patterns and revealed a number of errors that Grade 12 South African students made in their final examinations. The analysis hinged on students' answers to Question 3 and this question was mainly on coordinate geometry (specify locations and describe spatial relationships using coordinate geometry and other representational systems) and transformation geometry (apply transformation and use symmetry to analyse mathematical situations). These sections of geometry require learners to mainly operate on levels 1 to 4 of the Van Hiele hierarchy. However, the results revealed that the majority of students in Grade 12 operate at level 2 of Van Hiele's levels of geometrical thought. Whilst the research did not establish the main reason behind this, literature validates that most mathematics teachers are not grounded in instructional strategies that enable students to learn mathematics effectively. Hansen et al. (2014) indicate that teachers' vocabulary of geometry terms is pivotal in ensuring that students acquire the knowledge of the subject and that lack of it has been a source of errors. It was also established that most of the errors were those related to procedures for solving questions on geometry and because most of the learners were conceptually weak, their procedures were flawed too.

\section{Implications}

Examining the literature and the results derived from the study the first question that this study helped to answer was: How to help students understand high school geometry. The study of geometry, like the other sections of mathematics, starts from early childhood. The first geometrical concepts form the basis for the rest of geometry in school curricula. Thus the best approach involves changing how mathematics and especially geometry is taught before high school. Some points to consider are:

- Improve geometry teaching in the foundation and intermediate phases so that students' Van Hiele levels of geometrical thought are brought up to at least to the level of abstract or relational.

- Include more justifications, informal proofs and 'why' questions in geometry teaching during Foundation Phase and Intermediate Phase.
The Van Hiele levels explain the understanding of spatial ideas and how one thinks about them. The thinking process that one goes through when exposed to geometric contexts defines the levels of operation and they are not dependent on age (Battista, 2007; Van de Walle, 2004). Van de Walle (2004) insists:

While the levels are not age-dependent in the sense of the developmental stages of Piaget and a third grader or a high school student could be at level $0[\ldots]$ age is certainly related to the amount and types of geometric experience that we have. Therefore, it is reasonable for all children in K-2 range to be at level 0. (p. 347)

Hence, one can expect children in the first grade to be in the first level of Van Hiele's hierarchy - the visual level - as they are interacting with formal classroom geometry for the first time. This means children recognise geometric figures based on their appearance and not based on their properties. At this level, children are mainly learning the names of some shapes, such as square, triangle, rectangle and circle. At elementary level children should investigate geometric shapes so that they will reach the second Van Hiele level (descriptive or analytic). That is when they can identify properties of figures and recognise them by their properties, instead of relying on appearance. But all this requires teachers both at primary and secondary schools who are grounded in the content of geometry and are able to teach in ways that equip learners with conceptual knowledge and not only procedural knowledge. Teachers should from an early stage instruct children to use rulers, compasses and protractors to draw shapes.

\section{Acknowledgements}

I would like to acknowledge the Gauteng Department of Education who funded the main study of which this article is a part.

\section{Competing interests}

I declare that I have no financial or personal relationships that may have inappropriately influenced me in writing this article.

\section{References}

Atebe, H.U., \& Schäfer, M. (2011). The nature of geometry instruction and observed learning outcomes opportunities in Nigerian and South African high schools. African Journal of Research in Mathematics, Science and Technology Education, 15(2), 191-204.

Bahr, K., Bahr, L., \& De Garcia, L. (2010). Elementary mathematics is anything but elementary: Content and methods from a developmental perspective. London Cengage Learning.

Bassarear, T. (2012). Mathematics for elementary school teachers. (5th edn.). London: Brooks/Cole.

Battista, M. (2007). The development of geometric and spatial thinking. In F.K. Lester (Ed.), Second handbook of research on mathematics teaching and learning (pp. 843-908). Reston, VA: NCTM.

Berelson, B. (1952). Content analysis in communication research. New York, NY: The Free Press.

Burger, W.F., \& Shaughnessy, J.M. (1986). Characterizing the Van Hiele levels of development in geometry. Journal for Research in Mathematics Education, 17(1), 31-48. http://dx.doi.org/10.2307/749317

Centre for Development in Education (CDE). (2010). The maths and science performance of South Africa's public schools. Johannesburg: CDE.

Chambers, P. (2008). Teaching mathematics: Developing as a reflective secondary teacher. London: Sage Publications. 
Clement, D.H., Swaminathan, S., Hannibal, M.A.Z., \& Sarama, J. (1999). Young children's concepts of shapes. Journal of Research in Mathematics Education, 30(2), 192-212. http://dx.doi.org/10.2307/749610

Confrey, J. (1990). A review of the research on students' conceptions in mathematics, science, and programming. In C. Cazden (Ed.), Review of research in education (pp. 3-56). Washington, DC: American Educational Research Association. http:// dx.doi.org/10.2307/1167350

Cooke, H. (2007). Mathematics for primary and early years: Developing subject knowledge. (2nd edn.). London: Sage Publications. http://dx.doi.org/10.4135/ 9781446216040

De Villiers, M. (1998). An alternative approach to proof in dynamic geometry. In R. Lehrer, \& D. Chazan (Eds.), Designing learning environments for developing understanding of geometry and space (pp. 369-393). Hillsdale, NJ: Lawrence Erlbaum Associates.

Department of Education. (2006). The national policy framework for teacher education and development in South Africa. More teachers; better teachers. Pretoria: DOE. Available from http://www.education.gov.za/LinkClick.aspx?fileticket=WEagYcA7 V7U $\% 3 \mathrm{~d} \&$ tabid $=100 \& \mathrm{mid}=403$

Ding, L., \& Jones, K. (2006). Teaching geometry in lower secondary school in Shangai, China. Proceedings of the British Society for Research into Learning Mathematics, 26(1), 41-46. Available from http://www.bsrlm.org.uk/IPs/ip26-1/ BSRLM-IP-26-1-8.pdf

Drews, D. (2005). Children's errors and misconceptions in mathematics. In A Hansen (Ed.), Understanding common misconceptions in primary mathematics (pp. 14-22). London: Learning Matters Ltd.

González, G., \& Herbst, P. (2006). Competing arguments for the geometry course: Why were American high school students supposed to study geometry in the twentieth century? The International Journal for the History of Mathematics Education, 1(1) century?

Hansen, A., Drews, D., \& Dudgeon, J. (2014). Children's errors in mathematics. London: Sage Publications Ltd.

Hiebert, J. (Ed.) (1986). Conceptual and procedural knowledge: The case of mathematics. Hillsdale, NJ: Lawrence Erlbaum.

Jones, K. (2003). Issues in the teaching and learning of geometry. In L. Haggarty (Ed), Aspects of teaching secondary mathematics: Perspectives on practice (pp. 121-139). London: Routledge Falmer.

Kerlinger, F.N. (1986). Foundations of behavioural research. (3rd edn.). New York, NY: Holt, Rinehart and Winston.

Kilpatrick, J., Swafford, J., \& Findell, B. (2001). Adding it up: Helping children learn mathematics. Washington, DC: National Academy Press.

Lim, S.K. (2011). Applying the Van Hiele theory to the teaching of secondary schoo geometry. Teaching and Learning, 13(1), 32-40.

Luneta, K. (2008). Error discourse in fundamental physics and mathematics: Perspectives of students' misconceptions. In ICET 2008 International Council on Education for Teaching (ICET) 2008 international yearbook (pp 386-400). Wheeling, IL: National-Louis University Press.
Luneta, K. (2014). Foundation phase student teachers' (limited) knowledge of geometry. South African Journal of Childhood Education, 4(3), 71-86.

Luneta, K., \& Makonye J.P. (2011). Undergraduate students' preferences of knowledge to solve particle mechanics problems. Journal for Science and Mathematics Education for Southeast Asia, 34(2), 237-261.

Michael, L.C. (2001). Teaching contextually: Research, rationale, and techniques for improving student motivation and achievement in mathematics and science. Waco, TX: CCI Publishing Inc.

Musser, L.G., Burger, W.F., \& Peterson, B.E. (2011). Mathematics for elementary teachers. International Student Version. (9th edn.). Hoboken, NJ: John Wiley and Sons (Asia).

Pegg, J. (1985). How children learn geometry: The Van Hiele model. Australian Mathematics Teacher, 41(2), 2-4.

Piaget, J. (1971). Science of education and the psychology of the child. New York, NY: The Viking Press.

Pusey, E.L. (2003). The Van Hiele model of reasoning in geometry: A literature review. Unpublished master's thesis, North Carolina State University, Raleigh, NC, United States. Available from http://.www.lib.ncsu.edu/theses/available/etd-04012003 202147/unrestricted/etdo.pdf

Rittle-Johnson, B., \& Alibali, M.W. (1999). Conceptual and procedural knowledge of mathematics: Does one lead to the other? Journal of Educational Psychology, 9(1), 175-189. http://dx.doi.org/10.1037/0022-0663.91.1.175

Shavelson, R.J., Ruiz-Primo, M.A., \& Wiley, E.D. (2005). Windows into the mind. Higher Education, 49, 413-430. http://dx.doi.org/10.1007/s10734-004-9448-9

Siyepu, S.W. (2005). The use of Van Hiele theory to explore problems encountered in circle geometry: A Grade 11 case study. Unpublished master's thesis. Rhode University, Grahamstown, South Africa.

Swan, M. (2001). Dealing with misconceptions in mathematics. In P Gates (Ed.), Issues in mathematics teaching (pp. 147-165). London: Routledge Falmer.

Van de Walle, J.A. (2004). Elementary school mathematics: Teaching developmentally. New York, NY: Longman.

Van der Lith, D. (2007). Mathematics: Study and master Grade 12 learners' book. Cape Town: Cambridge University Press.

Van der Sandt, S. (2007). Pre-service geometry education in South Africa: A topical case? IUMPST: The Journal, 1 (Content Knowledge), 1-9.

Van der Sandt, S., \& Nieuwoudt, H.D. (2003). Grade 7 teachers' and prospective teachers' content knowledge of geometry. South African Journal of Education 23(3), 199-205.

Van Hiele, P.M. (1986). Structure and insight: A theory of mathematics education. Orlando, FL: Academic Press.

Van Hiele, P.M. (1999). Developing geometric thinking through activities that begin with play. Teaching Children Mathematics, 5, 310-316.

Verschaffel, L., Greer, B., \& De Corte, E. (2000). Making sense of word problems. Lisse, The Netherlands: Swets \& Zeitlinger. 


\section{Appendix 1}

2008 NATIONAL EXAMINATION GRADE 12 PAPER 2 QUESTION 3 (SIMPLIFIED)

3.1. Given that $P(-\sqrt{ } 2 ; \sqrt{ } 3)$ is on a Cartesian plane. Determine the coordinates of the image of $P$ if:

3.1.1 $\mathrm{P}$ is reflected in the line $y=x$.

3.1.2 $\mathrm{P}$ is rotated about the origin through $180^{\circ}$.

3.2 Polygon $A B C D E$ on a grid has coordinates $A(1 ; 1), B(1 ; 2), C(2 ; 3), D(3 ; 2)$ and $D(2 ; 2)$. Each of the points $A B C D E$ on the grid is rotated $90^{\circ}$ about the origin in a clockwise direction.

3.2.1 Write down the coordinates of $D^{\prime}$, the image of $D$.

3.2.2 Sketch and label the vertices $A^{\prime} B^{\prime} C^{\prime} D^{\prime} E^{\prime}$ on the image of $A B C D E$.

3.2.3 The polygon $A^{\prime} B^{\prime} C^{\prime} D^{\prime} E^{\prime}$ is then enlarged through the origin by a factor 3 in order to give the polygon $A^{\prime \prime} B^{\prime \prime} C^{\prime \prime} D^{\prime \prime} E$ ". Write down the coordinates of $D^{\prime \prime}$, the image of $D^{\prime}$.

3.2.4 Write down the general transformation of a point $(x ; y)$ in ABCDE to $\left(x^{\prime \prime} ; y^{\prime \prime}\right)$ after ABCDE has undergone the above two transformations. That is, rotation in a clockwise direction through an angle of $90^{\circ}$, followed by an enlargement through the origin by a factor of 3 .

3.2.5 Calculate the ratio of area $A B C D E: a r e a ~ A " B " C " D " E "$. 